\title{
D. JOSÉ MARÍA SALVADOR Y BARRERA, OBISPO, SENADOR Y ACADÉMICO
}

A Manuel Ponce Oña, in memoriam

\author{
Pablo Ramirez Jerez \\ Real Academia de Ciencias Morales y Politicas
}

\section{RESUMEN / ABSTRACT}

El presente artículo traza la semblanza intelectual y profesional del religioso José $\mathrm{M}^{\mathrm{a}}$ Salvador y Barrera (1851-1919), natural de Marchena, que llegó a ser Rector del Colegio del Saco-Monte de Granada,Obispo de Tarazona, Obispo de Madrid-Alcalá, Arzobispo de Valencia y Senador, y que dedicó todos sus esfuerzos a defender la enseñanza religiosa y la acción social de la Iglesia desde los altos puestos que ocupó. Fue además un excelente orador y persona de gran cultura, siendo reconocida su labor por las Reales Academias de la Historia y de Ciencias Morales y Políticas, que le eligieron como académico de número. El obispo Salvador fue realmente uno de los prelados más competentes y aperturistas de los dos primeros decenios del siglo XX.

This paper traces the intellectual and professional semblance of the religious José $M^{a}$ Salvador y Barrera (1851-1919), born in Marchena, province of Seville, who became Rector of the Sacro-Monte College in Granada, Bishop of Tarazona and Madrid-Alcalá, Archbishop of Valencia and Senator, who dedicated his efforts to defend religious education and the social labour of the Church from the high positions he held. Furthermore, he was an excellent preacher and a person of great culture, being his work recognized by the Royal Academy of Moral and Political Sciences and the Royal Academy of History, which chose him as a full member. Bishop Salvador was indeed one of the most competent and open-minded prelates in the first two decades of the $20^{\text {th }}$ century. 


\section{SALVADOR Y BARRERA Y SU CARRERA ECLESIÁSTICA}

José $\mathrm{M}^{\mathrm{a}}$ Salvador y Barrera nació en Marchena el 1 de septiembre de 1851; realizó estudios eclesiásticos y literarios en el SacroMonte de Granada, donde ingresó con una beca a los 16 años. Si bien abandonó su villa natal, como marchenero mantuvo siempre su devoción por la Virgen de los Desamparados y el Santísimo Cristo de San Pedro. Licenciado en Filosofia y Letras y Doctor en Derecho Canónico y Civil, consiguió una canonjía en la catedral de Granada, en cuyo Cabildo desempeñó sucesivamente los cargos de administrador general, tesorero, proveedor y secretario capitular.

En 1881 fue nombrado Rector del Colegio del Sacro-Monte, logrando en 1895 que se restableciera la Facultad de Derecho; fue reelegido para el cargo de Rector catorce veces seguidas. Alli ocupó durante más de veinte años la cátedra de Historia crítica de España, enseñando además literatura, psicología, lógica y ética. Desde su puesto de Rector, promovió la fundación de la Academia Dionisiana, en la que teólogos y juristas debatían ante sus compañeros de curso sobre un tema dado. Se encargó de leer el discurso inaugural del curso 1899-1900 en el Sacro-Monte, que llevó por título La libertad de enseñanza en sus aspectos histórico y legal (Granada, Imp. de José López Guevara, 1899. 55 p.) Veremos como este asunto será una constante a lo largo de toda su vida.

De esta etapa granadina data también su Discurso leído en la inauguración de la velada literaria en honor de Santo Tomás de Aquino en el... Sacro-Monte de Granada (Granada, Imp. de José López Guevara, 1898. 14 p.), uno de los pocos trabajos en los que habla de su gran referente filosófico.

Pero Salvador y Barrera estaba llamado a ocupar puestos de mayor responsabilidad en la jerarquía eclesiástica española. En efecto, gracias a su relación con el auditor de la nunciatura, monseñor Bavona ${ }^{1}$, y a su intervención en las negociaciones con el nuevo Ministerio de Instrucción Pública para regular el tema

1 CÁRCEL ORTÍ, Vicente: “José María Salvador y Barrera”.Diccionario Biográfico Español, t. XLV, p. 371. Madrid: Real Academia de la Historia, 2011 
de la enseñanza, León XIII le preconizó Obispo de Tarazona el 16 de diciembre de 1901, encargándose de dirigir esta diócesis entre abril de 1902 y diciembre de 1905; al mismo tiempo, en abril de 1902 fue nombrado Administrador apostólico de la Diócesis de Tudela. Aprovechando la ocasión, publicó la Carta pastoral que el Obispo de Tarazona dirige con motivo de la entrada en su diócesis al clero y sus fieles de la misma (Granada, Imp. de José López Guevara, 1902. 26 p.)

Continuando con su incansable labor pedagógica, el nuevo obispo reformó el Seminario de Tarazona ampliando grandemente sus estudios, para lo que creó las cátedras de Arqueología cristiana, Lengua castellana, Canto litúrgico y Estudios sociales. En otro orden de cosas, como persona preocupada por la acción social, apoyó también el desarrollo de las corrientes sindicales católicas, e intentó solventar los graves problemas planteados por la cuestión social "en clave de justicia"; además, hizo venir de Valencia al jesuita padre Vicent, organizador de las obras sociales en España ${ }^{3}$, para que enseñara a su clero, y así se fundaron diversas Cajas de crédito, escuelas nocturnas y cooperativas en diferentes localidades de ambas diócesis ${ }^{4}$. Además de engrandecer el Seminario de Tarazona, el obispo Salvador se preocupó de la restauración del templo mudéjar de San Francisco.

Posteriormente fue trasladado a la diócesis de Madrid-Alcalá, de la que tomó posesión como Obispo el 10 de mayo de 1906 y en donde prosiguió plenamente con el desarrollo de sus ideas pedagógicas, orientadas fundamentalmente a la adecuada formación del clero, y de acción social católica; así, en octubre de ese mismo año inauguró el Seminario Mayor, rodeándose de un valioso círculo de colaboradores, y donde estableció las cátedras de Estudios

2 CUENCA TORIBIO, José Manuel: Catolicismo social y politico en la España contemporánea (1870-2000). Madrid: Unión Editorial, 2003, p. 157

3 Antonio Vicent (1837-1912), además de notable biólogo, fue uno de los pioneros del apostolado social en España, fundó varios Círculos Obreros Católicos, posteriormente trasformados en Escuelas de Reforma Social y colaboró en la difusión del ideario social a través de las Semanas Sociales Españolas (1906-1912)

4 OLMOS Y CANALDA, Elías. Los prelados valentinos. Valencia: Semana Gráfica, 1949 , p. 362 y ss. 
Sociales, de la que se ocuparía el sacerdote pontevedrés Javier Vales Failde ${ }^{5}$,Oratoria, a cargo de Luis Calpena ${ }^{6}$, Arqueologia, regentada por el historiador Manuel Gómez Moreno, así como otras de Filosofia superior, Apologética y Agricultura. Con todo ello, el Seminario de Madrid se convirtió en un gran centro de estudios eclesiásticos, destacando la creación de la facultad de Sagrada Escritura, la segunda del mundo después de la de Roma. Al año siguiente tuvo lugar la fundación del Seminario Menor de Alcalá, especializado en humanidades y filosofia. No acabarian aquí sus creaciones educativas, pues el 31 de octubre de 1908 se inauguró en Madrid la Academia Universitaria Católica (Instituto de Altos Estudios Sociales), proyecto impulsado por el cardenal Sancha y el propio Salvador, y en aquel acto pronunció el obispo un discurso inaugural declarando que "el centro docente venía a realizar el sueño de toda su vida, objeto de todos sus afanes"7. Es de resaltar que en este centro impartieron sus lecciones diversos académicos de la Real Academia de Ciencias Morales y Politicas, como el ya citado Javier Vales, Rafael Marín Lázaro, Juan Zaragüeta, Eduardo de Hinojosa o Severino Aznar.

En diciembre de 1906 se publicó la Carta pastoral que el Excmo. e Ilmo. Sr. Doctor D. José $M^{a}$ Salvador dirige al clero y fieles de su diócesis con motivo de la inauguración del nuevo Seminario $^{8}$ (Madrid, 1906), en la que criticaba las nuevas leyes laicas del gobierno, como la referente al matrimonio civil, y la presentación del proyecto de Ley de Asociaciones en lo relativo a las congregaciones religiosas; en dicha pastoral el obispo se proponía exponer lo que el derecho natural y los principios del cristianismo y del derecho político enseñan sobre esa materia. Así, la pastoral recuerda cómo León XIII reprueba estas leyes antirreligiosas ya

5 Javier Vales Failde (1872-1923), sacerdote y Juez auditor en el Supremo Tribunal de la Rota de la Nunciatura, ingresó en la Real Academia de Ciencias Morales y Políticas en 1920 con un discurso titulado La Rota española.

6 El teólogo Luis Calpena Ávila (1860-1921), fue uno de los grandes oradores de su época y miembro de la Real Academia de la Historia, en la que ingresó en 1918 con un discurso titulado Los Concilios de Toledo en la construcción de la nacionalidad española.

7 Anales de la Academia Universitaria Católica, año VII, $n^{\circ} 6$ (sept. 1915), p. 202

8 Vid. La Ciudad de Dios, vol. LXXI, n VIII, 20 de diciembre de 1906, p. 644-662 
aprobadas en Francia "contrarias al derecho natural y evangélico y a la constante tradición que hay para asociarse libremente en un género de vida, no solo honesto en sí mismo, sino santo; leyes contrarias igualmente al derecho absoluto que tiene la Iglesia de fundar institutos religiosos exclusivamente dependientes de ella..." Además, el artículo 13 de la Constitución entonces vigente reconocía el derecho natural de asociación, sin mayor limitación que la de que los socios se reúnan para algún fin lícito de la vida humana. Igualmente importante, en lo referente a derecho canónico, fue la carta titulada El matrimonio: carta pastoral que el Excmo. e Ilmo. señor Dr. D. José María Salvador y Barrera, Obispo de Madrid-Alcalá dirige a sus diocesanos con motivo del santo tiempo de cuaresma, acerca del Decreto Ne temere sobre el matrimonio (Madrid, 1908), en la que analiza el decreto emitido por Pío X en 1907.

Además de esta faceta pedagógica, el obispo Salvador siguió con su labor apostólica, y así instituyó las juntas parroquiales, convocó y presidió el primer Sínodo diocesano de Madrid-Alcalá en febrero de 1909, inauguró la Casa del Instituto de Damas Catequistas, instituyó el Montepío del Clero para mejorar la situación económica de los sacerdotes, creó la Liga Nacional de Defensa del Clero y proveyó de curas propios a todas las parroquias de la diócesis; bajo sus auspicios se celebró en Madrid el Congreso Eucarístico Internacional en 1911. Durante su pontificado en esta diócesis se abrieron al culto las iglesias de San Ramón, San Miguel, Nuestra Señora de Gracia, la Concepción y la de Covadonga, además de la cripta de la catedral de la Almudena. Por otro lado, dotó de seguros contra incendios a casi doscientas iglesias y ciento treinta casas rectorales de la diócesis de Madrid-Alcalá.

De esta época datan la Carta pastoral explicando las normas dadas por el Cardenal Aguirre sobre la acción católico-politico y social de España (Madrid, 1911) y otra publicada con el título de Fiestas Constantinianas (Madrid, 1914) para conmemorar los 1600 años del famoso decreto de Constantino del año 313, el Edicto de Milán. Allí expone el triunfo de la Iglesia tras siglos de persecución, cuya acción se impuso finalmente a los paganos por medio de la práctica de las virtudes cristianas. El obispo hace un paralelismo entre aquellas persecuciones y las coetáneas, 
manifestada en las políticas laicas y secularizadoras. A pesar de tanta actividad, tuvo tiempo para prologar la obra de Ramón Méndez Gaite Vidas santas: segunda serie de Joyas Cristianas (Madrid, 1908, 2 vol.)

Finalmente, el 14 de diciembre de 1916, el papa Benedicto XV le preconizó Arzobispo de Valencia, incorporándose a su nuevo destino el 26 de marzo de 1917. En esta ciudad prosiguió incansable con su labor, mandó construir las parroquias de San Miguel, San Ramón y Nuestra Señora de Covadonga, creó el Cabildo de Párrocos de la ciudad y reestructuró los límites del arciprestazgo. En su Carta pastoral a sus diocesanos con motivo de su proclamación al arzobispado de Valencia (Madrid, 1917) enfatizaba "la necesidad de la Iglesia como sociedad y como autoridad" " Estableció asimismo una serie de conferencias morales y litúrgicas para los sacerdotes, a los que exhortaba a que estudiasen la doctrina social de la Iglesia y el nuevo Código de Derecho Canónico de 1917, promulgado por Benedicto XV. Suprimió el patronato laico sobre algunas parroquias, creó la Cofradía del Santísimo Sacramento y la Hermandad del Santo Cáliz de la Cena, reorganizó la enseñanza religiosa, mandó construir la Casa de los Obreros Católicos de San Vicente Ferrer e impulsó su periódico, "El Pueblo Obrero". En la Universidad Pontifica de Valencia, por su parte, creó las cátedras de Griego bíblico, Arqueología e Historia bíblica e Historia de los dogmas, además de potenciar los estudios de hebreo. Como arzobispo de Valencia es autor además de otras notables pastorales, como La palabra de Dios (Valencia, 1916), y San Vicente Ferrer. Carta pastoral (Valencia, 1919).

\section{SALVADOR Y BARRERA EN EL SENADO. LA CUESTIÓN DE LA ENSEÑANZA}

Además de sus altos cargos eclesiásticos, el obispo Salvador fue senador por el Arzobispado de Toledo en las legislaturas de 19071908, 1910-1911, 1914-1915 y 1916-1917, y por el de Valencia en la legislatura 1918-1919, si bien no juró y optó por derecho propio.

9 OLMOS Y CANALDA, op. cit., p. 367 
Entre sus intervenciones, ciertamente abundantes, destacan discursos necrológicos sobre diversos miembros de la jerarquía eclesiástica también senadores, como el cardenal Sancha ${ }^{10}$ o el obispo de Osma José $\mathrm{M}^{\mathrm{a}}$ García Escudero ${ }^{11}$, sobre libros de texto, impuestos..., pero sobre todo intervino activamente en los debates del Senado en las cuestiones referentes a la enseñanza. Así, por ejemplo, se oyó su voz contra de la ley que presentó el presidente Canalejas prohibiendo el establecimiento de nuevas Asociaciones pertenecientes a Órdenes o Congregaciones religiosas, canónicamente reconocidas, sin la autorización del Ministerio de Gracia y Justicia, más conocida por la historiografia como la "Ley del candado". El obispo intervino al respecto en la sesión de 29 de octubre de 1910 defendiendo la labor educativa de las órdenes religiosas $^{12}$.

La aprobación de dicha ley en diciembre de 1910 provocó enormes protestas de los medios católicos y supuso la ruptura de relaciones con el Vaticano, y tanto Canalejas como el obispo Salvador y Barrera, a quienes unía una buena amistad, realizaron las oportunas gestiones conducentes a la normalización de las relaciones. También en el Senado defendió la enseñanza religiosa, logrando posponer la aplicación de las medidas legislativas más laicas.

En el debate sobre el presupuesto para el Ministerio de Instrucción Pública que se celebró en diciembre de 1912, intervino el Obispo para decir que no solamente aumentando el presupuesto se aumenta la cultura; esto debe ir acompañado de corrección y disciplina social, creando cierto ambiente de orden y severidad moral que estimule la acción de la enseñanza. En su larga y documentada intervención insiste en sus ideas sobre la educación y la actitud que debe tener el Estado:

10 Diario de las sesiones de Cortes. Senado. Sesión del viernes 26 de febrero de 1909. Legislatura 1908-1909, p. 2017

11 Diario de las sesiones de Cortes. Senado. Sesión del martes 23 de marzo de 1909. Legislatura 1908-1909, p. 2538-2539

12 Diario de las sesiones de Cortes. Senado. Sesión del sábado 29 de octubre de 1910. Legislatura 1910, p. $782-784$ 
"La función de la enseñanza [...] es una función social, sin que el Estado tenga en este asunto más que una acción meramente tutelar y supletoria. Este es un principio que tiene categoría de axioma entre todos los tratadistas de Derecho politico, de la derecha y de la izquierda, de la escuela liberal y de la conservadora. [...] la enseñanza no es otra cosa que el apetito reciproco que se establece entre el que sabe y tiende a comunicar lo que sabe y entre el que no sabe y quiere aprender lo que ignora. ${ }^{13}$ "

Para el obispo, solo en la sociedad está la facultad de aprender y la libertad y el derecho de enseñar, sin que sea atribución del Estado más que amparar este derecho y esta libertad, pero de ninguna manera dar lo que no tiene. Esta doctrina se apoya también en los más insignes tratadistas del derecho, y cita a los franceses Portalis y Thiers, así como antiguas intervenciones de Sagasta y Ruiz Zorrilla sobre la libertad de enseñanza. Defender que la enseñanza es función del Estado es el comunismo puesto en acción. Se muestra igualmente opuesto al concepto de escuela neutra o laica, implantado en Francia en 1882, cuya razón de ser no era otra que lograr la ruptura completa entre la sociedad y la religión. Solo Francia y Portugal tienen escuelas laicas. Critica que "personas cultas y escépticas en materia de religión confien en una especie de edad paradisíaca que ha de venir con la cultura sin religión y sin moralidad, sin otro fundamento para ello que aquellos sueños hegelianos que se han terminado por trocarse en los ideales de la escuela positivista moderna". Para su intervención aportó el Obispo datos sobre la enseñanza religiosa en diversos países europeos, así como declaraciones de grandes estadistas liberales, como Robert Peel, Lord Derby, Gladstone, Lord Russell, Sir Stafford Northcote, Guizot, y Cousin, todas ellas favorables a la educación religiosa.

En realidad, durante estos años, la cuestión escolar era un problema derivado de la cuestión religiosa, y en ella los obispos jugaron un papel importante a la hora de apoyar o bloquear proyectos del gobierno en el tema educativo. El Senado hizo las veces de caja de resonancia de las opiniones episcopales, generalmente en contra de aquellas iniciativas que disminuyeran el poder eclesiástico en el

13 Diario de las sesiones de Cortes. Senado. Sesión del jueves 12 de diciembre de 1912. Legislatura 1911-1914, p. 2820-2825 
ámbito de la enseñanza. Así, junto al obispo Salvador, destacaron el obispo de Salamanca, Tomás Cámara, el cardenal Spínola, ambos en contra del Estado docente, los arzobispos de Toledo, Zaragoza y Valladolid, y los obispos de Jaca y Guadix, todos ellos en los debates de la denominada "ley del candado". Junto a Salvador y Barrera destacó Antolín López Peláez, obispo de Jaca y de Tarragona, por su posición en la defensa de la enseñanza católica. Además del Senado, los Boletines Oficiales de las respectivas diócesis servian para trasmitir la doctrina católica respecto a la educación y a la enseñanza ${ }^{14}$.

También fueron importantes las pastorales sobre la cuestión religiosa que se publicaron por aquellas fechas, destacando $E l$ hombre mutilado por la escuela neutra, del obispo de Vic, Josep Torras en 1908, El laicismo en la enseñanza, de Salvador y Barrera en 1914, o la Carta pastoral sobre el laicismo emitida por el cardenal Guisasola en 1915, miembro, como Salvador, de la Real Academia de Ciencias Morales. Todas estas opiniones e intervenciones forman una doctrina sólida y unitaria en materia de educación, una voz apologética de la doctrina y la práctica de la educación católica. En algunas ocasiones se expresaba colectivamente todo el episcopado español, como el Mensaje de los Señores obispos reunidos con motivo del Congreso Católico de Santiago de Compostela a S.M. el Rey Don Alfonso XIII ${ }^{5}$, una crítica a la política secularizadora de los gobiernos liberales. La cuestión de las escuelas laicas, cerradas por el gobierno de Maura, motivó también la Exposición dirigida al Sr. Presidente del Consejo de Ministros contra la existencia de las escuelas llamadas laicas ${ }^{16}$, ante la pretensión de reabrirlas por parte del gobierno de Canalejas. Igualmente se opusieron los obispos en bloque al Proyecto de codificación de la enseñanza, de 1912, que veían como expresión inequívoca de una tendencia secularizadora, y publicaron la carta Prelados españoles al Presidente del Consejo de Ministros sobre la Codificación de la legislación de Enseñanza ${ }^{17}$.

14 Vid. F. MARTÍN HERNÁNDEZ, "La actitud del episcopado". En Historia de la educación en España y América, vol. 3: La educación en la España contemporánea (1789-1975), p. 560-568. Madrid, Fundación Santa María, 1994

15 Boletín Oficial Eclesiástico del Arzobispado de Toledo, 1902, p. 403

16 Boletín Oficial Eclesiástico del Arzobispado de Burgos, 1909, p. 349-355

17 Boletín Oficial Eclesiástico del Arzobispado de Toledo, 1912, p. 447-451 
Siguiendo con este asunto, el obispo Salvador se vio obligado a mediar entre el poder civil y grupos católicos con motivo del mitin pronunciado por Herrera Oria en el salón de conferencias de "El Debate" en marzo de 1913 que llevó por título En defensa de la enseñanza del catecismo, un beligerante discurso de protesta contra el intento del gobierno de Romanones de legislar en materia de enseñanza religiosa ${ }^{18}$.

En otro orden de cosas, y como muestra de otros asuntos que también requerían su atención, intervino para oponerse a la concesión al rey de Italia de la distinción de coronel honorario de un regimiento español, debido a la politica anticlerical que llevaba a cabo el gobierno italiano ${ }^{19}$. Igualmente, con motivo del fallecimiento del senador Marcelino Menéndez y Pelayo, y como representante de la Iglesia en el Senado, intervino con las siguientes palabras:

"He pedido la palabra, Sres. Senadores, para adherirme en nombre de la Iglesia, que tengo el honor de representar aquí, a la expresión de duelo que hizo la Cámara ayer en honor del Sr. Menéndez y Pelayo, porque si el inmortal poligrafo fue y será perpetuamente honra insigne de la patria y ornamento clarisimo de las letras y ciencias españolas, también fue un hijo preclaro de la Iglesia, devoto y fervorosísimo, cuya palabra y cuya pluma incomparable, lo mismo que su entendimiento extraordinariamente genial y poderoso, estuvo siempre al servicio de sus derechos, de su dogma y de su gloriosa historia. Por eso la Iglesia, que en estos días de dolor nacional eleva sus oraciones por el sapientísimo propugnador y defensor invencible de la verdad cristiana, prestará su concurso y bendecirá todo lo que hagan el Estado y el pueblo español para honrar la memoria de Menéndez y Pelayo y en sufragio de alma"no.

18 Recogido en las Obras Completas de Herrera Oria, t. V, p. 39-46. Madrid: Biblioteca de Autores Cristianos, 2004

19 Diario de las sesiones de Cortes. Senado. Sesión del viernes 17 de marzo de 1911. Legislatura 1911 , p. $122-123$

20 Diario de las sesiones de Cortes. Senado. Sesión del martes 21 de mayo de 1912. Legislatura 1911-1914, p. 1680 


\section{SALVADOR Y BARRERA Y LAS REALES ACADEMIAS}

Salvador y Barrera era un buen orador y persona de vasta cultura. A su saber polifacético unía un espíritu amplio y expansivo, abierto a nuevos conocimientos y listo para adoptar las posiciones más conciliadoras en las relaciones entre la Iglesia y el Estado, siempre que se respetasen los fueros y derechos de aquella. Fue un buen representante de aquellos prelados intelectuales que tanto abundaron a principios del siglo XX, una época en la que cada orden religiosa publicaba sus propias revistas culturales en un intento de hacer frente a la secularización. Ello le abrió las puertas de las dos Academias que le tuvieron entre sus miembros de número: la Real Academia de Ciencias Morales y Políticas y la Real Academia de la Historia.

\subsection{La Real Academia de Ciencias Morales y Políticas}

La Real Academia de Ciencias Morales y Políticas fue creada por la Ley de Instrucción Pública de 1857, siendo igual en categoría a las cuatro entonces existentes (Real Academia de la Lengua, de la Historia, de Bellas Artes de San Fernando y de Ciencias Exactas, Físicas y Naturales). A lo largo de su historia, más de 285 personalidades españolas de todos los campos de las ciencias sociales y la política han tenido asiento en su sede, ubicada en la Casa de los Lujanes de Madrid. Entre ellos ha habido economistas, historiadores, filósofos, políticos, juristas, sociólogos, pedagogos, y 24 religiosos, de los que tres figuran actualmente en la nómina de académicos: Alfonso López Quintás, Olegario González de Cardedal y Antonio $\mathrm{M}^{\mathrm{a}}$ Rouco Varela. De muchos de ellos solo ha quedado su discurso de ingreso como muestra de su paso por la Academia. Sin embargo, todos tienen en común su alto nivel de estudios y formación, abundando los doctores en teologia y filosofia, mientras que otros destacan en derecho canónico. Merece la pena resaltar que de los 24 académicos religiosos, cuatro alcanzaron la dignidad cardenalicia: Ceferino González y Díaz-Tuñón, Victoriano Guisasola, Marcelo González Martín y Antonio $\mathrm{M}^{\mathrm{a}}$ Rouco Varela.

El 4 de abril de 1911 fue propuesto Salvador y Barrera para ocupar la medalla $\mathrm{n}^{\circ} 16$ de la Real Academia de Ciencias Morales 
y Políticas, vacante por el fallecimiento de D. Joaquín Costa. Contó con el aval de los académicos Joaquín Sánchez de Toca, el conde de Tejada de Valdosera, el marqués del Vadillo, Felipe Sánchez Román y el marqués de Teverga, siendo elegido finalmente el 18 de abril de 1911. Ingresó en la misma el 2 de junio de 1912 con un discurso titulado La ciencia de la educación tiene su lugar propio entre las ciencias morales; la contestación corrió a cargo del jurista Javier Ugarte y Pagés. Ese año de 1912 ingresaron en la Academia siete académicos, además del propio Salvador: los ministros Juan Armada Losada y Antonio López Muñoz, los juristas Rafael Altamira y Rafael de Ureña, el filósofo e historiador Adolfo Bonilla, el político y ateneísta Rafael de Labra, y el diputado y senador Ramón Fernández-Hontoria.

Ya se ha hecho notar la gran labor pedagógica que el obispo Salvador llevó a cabo en Granada, Tarazona y Madrid. En efecto, como puede observarse, la acción social y la educación fueron los ejes fundamentales de su actividad. Fue también un escritor fecundo sobre el tema de la enseñanza y la instrucción pública, sobre los que escribió, además del texto académico citado, varias pastorales y pronunció diversos discursos: La libertad de enseñanza en sus aspectos histórico y legal (Granada, 1899) ${ }^{21}$, tres cartas pastorales tituladas El Estado Docente (Madrid, 1910), La religión en sus relaciones con la educación y la enseñanza (Madrid, 1914), y La religión en sus relaciones con la enseñanza (Madrid, 1915), además de los discursos pronunciados en el Senado los dias 6 de noviembre de 1908, 5 y 7 de julio de 1910, con motivo de la discusión de la contestación al mensaje de la Corona, 23 de noviembre de 1910, 12 de diciembre de 1912 , y 5 de mayo de $1914^{22}$.

El mensaje de fondo de todos estos trabajos es la lucha que mantiene la Iglesia con el liberalismo contemporáneo en el complejo e importante asunto de la educación; la educación es fundamental

21 Se trata del discurso inaugural leído en la apertura del curso 1899-1900 en el Colegio-Seminario de Teólogos y Juristas del Sacro-Monte de Granada.

22 Todo ello recogido por el propio autor en la obra El Derecho cristiano y las enseñanzas de la Iglesia en sus relaciones con la instrucción pública: Colección de discursos parlamentarios y trabajos pastorales y académicos. Madrid: Imp. del Asilo de Huérfanos, 1915. 
para la prosperidad y el bienestar de los pueblos, por lo que el elemento revolucionario intentó siempre apropiarse de esta cuestión para llevar a cabo sus fines y propósitos alejándose de los principios cristianos. Se sustrajo la enseñanza pública de la familia y la sociedad para entregarla al Estado; así nace el "Estado docente", fundado en el principio "de que los niños pertenecen a la república antes que a sus padres" ${ }^{23}$. Esas ideas surgen principalmente con la Revolución Francesa y se implantaron en España menospreciando el papel de la Iglesia; ya se pusieron durante el reinado de Carlos III los primeros jalones de ese proceso, un monopolio docente que culminó en el Plan de Estudios de Gil de Zárate de 1845, basado en el principio jacobino de que "sólo donde reside la soberanía, reside el derecho de educar y formar hombres apropiados a los usos que necesita el Estado"24. También es criticable en este sentido, opina el obispo, la Ley Moyano de 1857, que apuntala las funciones del Estado docente. Se lamenta asimismo de que la opinión católica española, a diferencia de la francesa, haya estado tan apática a la hora de luchar contra esas ideas, y a ella van dirigidos estos trabajos y discursos, con el fin de "alcanzar alguna vez lo que de derecho nos pertenece y en justicia reclaman la libertad de la Iglesia, las prerrogativas de la familia y la sociedad y en progreso y auge de la ciencia cristiana en nuestra patria"25.

Así pues, no es de extrañar que el obispo Salvador escogiera como tema de su discurso de ingreso en la Real Academia de Ciencias Morales y Políticas la educación y el papel del Estado docente. En este discurso defendía, por supuesto, la implicación de la Iglesia en la enseñanza, ya que consideraba que la función docente es social y no política, por lo que también reclamaba libertad académica de enseñanza (que no de cátedra) y la autonomía de la Universidad $\mathrm{y}$ otras instituciones docentes del Estado. El nuevo académico opinaba que el derecho natural convertía a la familia en el órgano fundamental de la educación, siendo la ciencia educativa un dominio moral, criticando el carácter experimental y empírico de los nuevos métodos de enseñanza que se abrian paso en aquellos tiempos.

\footnotetext{
Op. cit., p. VI del prólogo.

Op. cit., p. IX del prólogo.

Op. cit., p. XII del prólogo.
} 
Afirmaba, además, que la enseñanza ni es función del Estado, ni cargo u oficio público, sino servicio público. El Estado, continúa, debe ejercer una acción tutelar y de promoción, pero sin monopolio ni dirección absorbente y exclusiva, ya que ello convierte la instrucción pública en un organismo burocrático y despótico. Para él, la verdadera educación consistía en la educación de la voluntad y el pensamiento, enseñando las obligaciones de la vida social e individual desde un punto de vista cristiano. En definitiva, quería mantener las prerrogativas que la Iglesia tenía en la función educativa, a la vez que criticaba la educación laica que, originada en el jacobinismo radical francés, se iba extendiendo por Europa. Al margen de estas consideraciones, el obispo Salvador muestra un gran conocimiento de la psicología de su tiempo.

El tema de la enseñanza fue un asunto muy tratado en la Academia $^{26}$. En efecto, muchos de los académicos que ingresaron entre 1900 y 1923 tenían o habían tenido relación con la docencia, o estaban implicados en diversas asociaciones educativas. Otros académicos tenían cargos de responsabilidad en el mundo de la instrucción pública y eran buenos conocedores de la materia. Así, varios de ellos ocuparon la cartera de Instrucción Pública, creada en 1901, mientras que otros fueron destacados miembros del Consejo de Instrucción Pública o directores generales de enseñanza y de organismos educativos similares. En este contexto tan comprometido con el mundo de la instrucción pública, además del obispo Salvador, otros cuatro académicos que ingresaron en aquellos años presentaron discursos relacionados directamente con la reforma de la educación en España: Amós Salvador y Rodrigáñez (La gramática en el examen de ingreso de la segunda enseñanza, 1903), José de Cárdenas (La libertad de enseñanza es el más poderoso y eficaz elemento de cultura nacional, 1905), Rafael Altamira (Problemas urgentes de la primera enseñanza en España, 1912) y Juan Armada Losada, marqués de Figueroa (De la educación moral, 1912). Todos ellos insistian en la necesidad de mejorar el nivel educativo, aunque algunos hacian hincapié en

26 DIEGO GARCÍA, Emilio de.1857-2007. La Real Academia de Ciencias Morales y Politicas: Cultura y politica en la España contemporánea. Madrid: Real Academia de Ciencias Morales yPoliticas, 2009, p. 260 y ss. 
evitar que el Estado monopolizase la educación, como Salvador, pidiendo que su actuación se limitase a labores de protección, inspección y vigilancia, y velando igualmente por la independencia de los establecimientos educativos privados.

\subsection{La Real Academia de la Historia}

Salvador y Barrera perteneció también a otra gran corporación científica con sede en Madrid, la Real Academia de la Historia. Fue propuesto en marzo de 1912 para ocupar medalla $\mathrm{n}^{\circ} 12$, vacante por el fallecimiento de Juan Facundo Riaño, por los académicos Bienvenido Oliver y Esteller, Francisco Fernández de Bethencourt, Juan Pérez de Guzmán, Adolfo Herrera, Pedro Novo y Colson, el marqués de Cerralbo y el duque de T'Serclaes ${ }^{27}$. Inicialmente fue elegido Federico Olóriz, quien falleció antes de tomar posesión. El obispo Salvador ingresó el 1 de marzo de 1914, en sesión presidida por el rey Alfonso XIII, con un discurso titulado El Padre Flórez y su España sagrada, siendo contestado por Fernández de Bethencourt.

En su discurso de ingreso, el primero dedicado a la figura de tan ilustre historiador en esa docta corporación, el obispo Salvador critica los falsos cronicones que tanto abundaron en España hasta el siglo XVIII y que tan mala influencia ejercieron sobre el desarrollo de los estudios históricos. Afortunadamente, el siglo XVIII trajo un nuevo movimiento cultural que daba la importancia debida la documentación histórica real y contrastada, con lo que se depuraron las fuentes narrativas medievales. En ese siglo, y en el capítulo de historia eclesiástica descuella la España Sagrada de Enrique Flórez. Fue este un prototipo de investigador concienzudo y viajero, con una enorme capacidad de trabajo, descubridor de innumerables documentos de gran valor histórico y fiel editor de los mismos. Una persona de tanta valía no podía dejar de llamar la atención, de tal manera que el rey Fernando VI le otorgó una generosa pensión para que trabajara libremente en su obra. Aparte de ello, publicó otra

27 MARQUÉS DE SIETE IGLESIAS. "Real Academia de la Historia: Catálogo de sus individuos. Noticias sacadas de su archivo". Boletín de la Real Academia de la Historia, 1979, t. CLXXVI, cuad. III, p., 511-512. 
serie de libros y enseñó Teología en la Universidad de Alcalá. Flórez falleció en 1773, y dejó su obra inconclusa en el volumen XXIX; sin embargo, el interés y admiración que suscitó fue tal, que Carlos III encomendó por Real orden su continuación a los agustinos, y así siguieron apareciendo volúmenes de la España Sagrada, en diferentes etapas, a cargo de los agustinos Manuel Risco (17351801), Antolín Merino (1745-1830) y José de La Canal (1768-1845). Tras la supresión de las órdenes religiosas el encargo pasó a la Academia de la Historia, destacando a tal efecto el historiador y teólogo Vicente de La Fuente (1817-1889) ${ }^{28}$, entre otros. Con esta obra, dice el nuevo académico, dio inicio el padre Flórez a la crítica histórica en España.

En el seno de esta Academia trabajó en la Comisión permanente de la España Sagrada, junto a los académicos Conde de Cedillo y Manuel Pérez Villamil; propuso continuar esta magna obra con los dos tomos correspondientes a la Diócesis de Madrid-Alcalá, ofreciéndose además a costear él mismo la impresión ${ }^{29}$,pero este proyecto quedó finalmente aplazado debido a su traslado a Valencia y a la muerte de Pérez-Villamil, acaecida en 1917. No obstante, El intento de recuperar la España Sagrada recalcaba su valor como una de las grandes obras de la historiografia española.

En 1919, tras pasar una temporada en el balneario pontevedrés de Mondariz, el arzobispo Salvador se desplazó a la residencia Bellas Vistas de los jesuitas de Vigo, donde se disponía a acompañarles en sus ejercicios espirituales. Allí murió repentinamente, el 4 de septiembre de 1919, tras sentirse indispuesto. A pesar de haber mandado construir un panteón en el cementerio de Marchena, su villa natal, fue enterrado en la Capilla de la Purísima de la Catedral Metropolitana de Valencia, después de haber recibido sus restos honores militares de Capitán general con mando en plaza ${ }^{30}$. Poco

\footnotetext{
28 Vid. Pablo RAMÍREZ JEREZ. "Vicente de la Fuente y Bueno, prototipo de historiador e investigador decimonónico". Revista General de Información y Documentación, 2014, 24:2, p. 373-388

29 Juan PÉREZ DE GUZMÁN Y GALLO. El arzobispo de Valencia, Excmo. e Ilmo. Sr. D. José María Salvador y Barrera. Boletin de la Real Academia de la Historia, 1919 , t. LXXV, cuad. II-IV, p. 355-358

30 OLMOS Y CANALDA, op. cit., p. 371
} 
antes de su fallecimiento, su nombre habia sido propuesto para cardenal de la Iglesia.

En el momento de su fallecimiento era poseedor de las siguientes condecoraciones y dignidades: Caballero de la Real y Distinguida Orden de Carlos III, Gran Cruz de Isabel la Católica, Gran Cruz del Mérito Naval y Gran Cruz de Alfonso XII. Fue también capellán de honor de Alfonso XIII y su predicador, y los prelados españoles le otorgaron el título de Examinador sinodal.

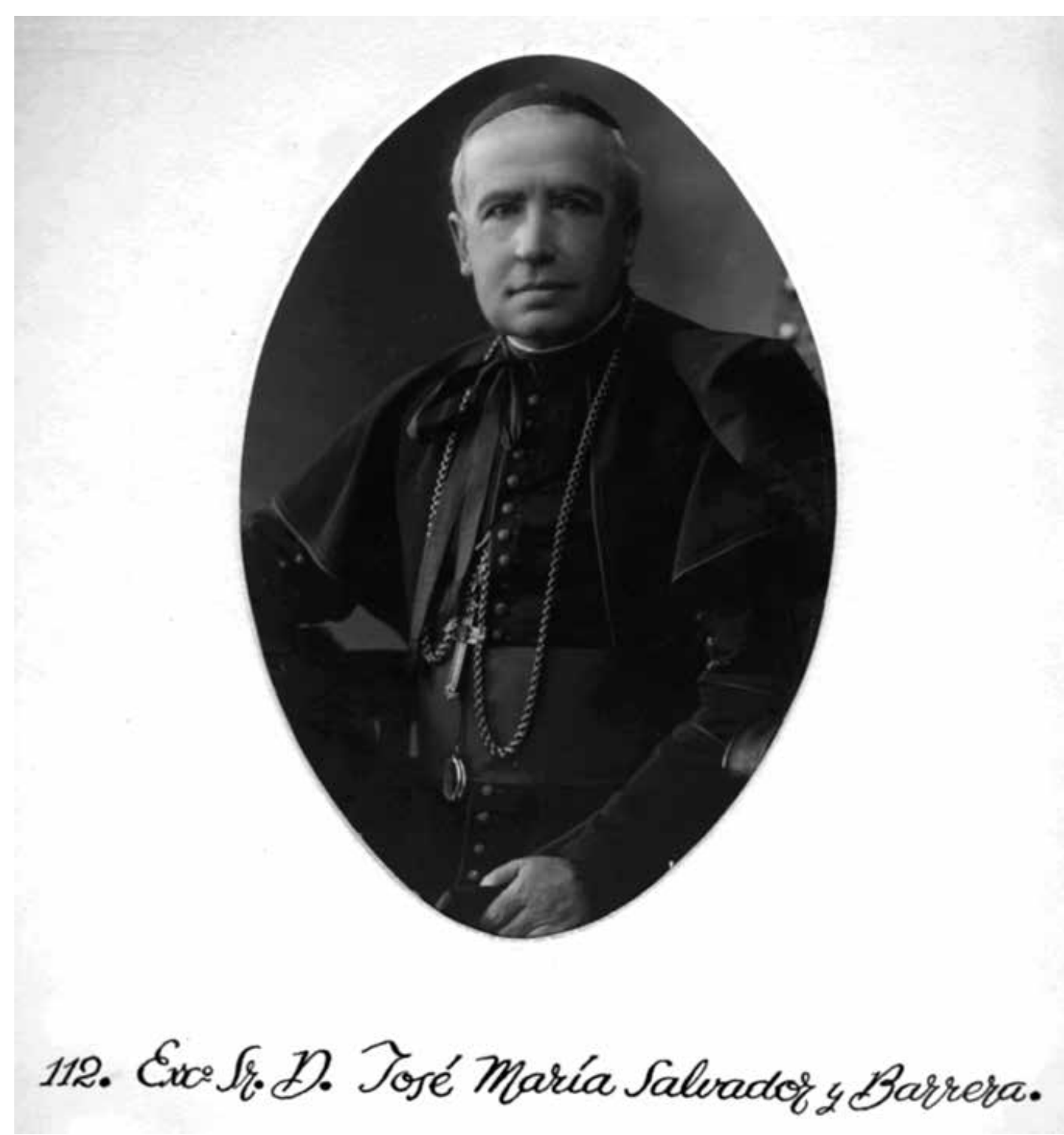

(C)Archivo de la Real Academia de Ciencias Morales y Politicas. 